See discussions, stats, and author profiles for this publication at: https://www.researchgate.net/publication/267622212

\title{
A Gallery of Root Locus of Fractional Systems
}

Conference Paper · August 2013

DOI: 10.1115/DETC2013-12470

\section{CITATION}

1

1 author:

José A. Tenreiro Machado

28. Polytechnic Institute of Porto

797 PUBLICATIONS 13,023 CITATIONS

SEE PROFILE

Some of the authors of this publication are also working on these related projects:

Project Development of Fractor and fractional order system View project

Project $\quad$ Multi-wave solution for nonlinear evolution equations and their applications in physics, biology, optics, and chemistry. View project
READS

141 


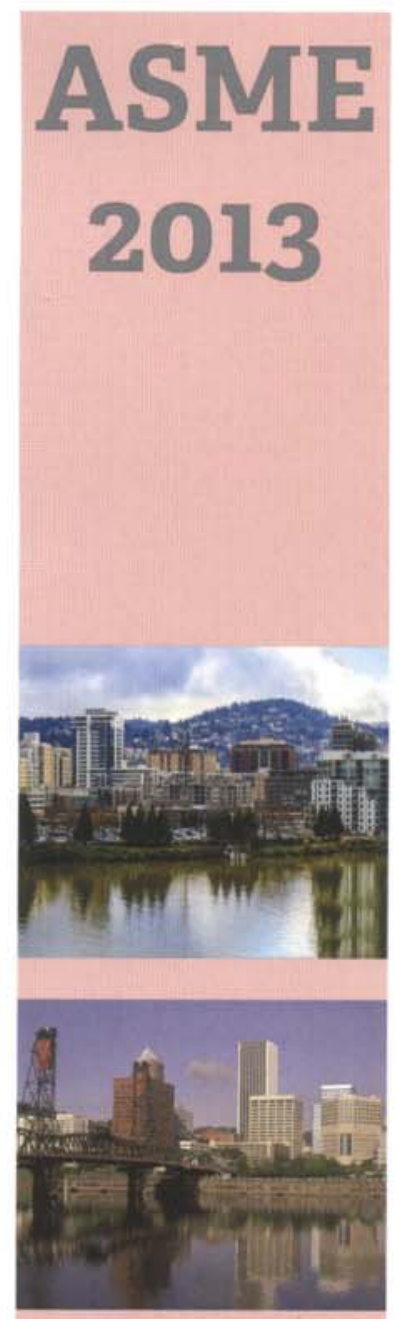

\section{INTERNATIONAL DESIGN} ENGINEERING TECHNICAL CONFERENCES \& COMPUTERS AND INFORMATION

\section{IN ENGINEERING CONFERENCE}

\section{August 4-7, 2013 Portland, Oregon}

- $15^{\text {th }}$ International Conference on Advanced Vehicle Technologies (AVT)

- $33^{\text {rd }}$ Computers and Information in Engineering Conference (CIE)

- 39th Design Automation Conference (DAC)

- $10^{\text {th }}$ International Conference on Design Education (DEC)

- $18^{\text {th }}$ Design for Manufacturing and the Life Cycle Conference (DFMLC)

- $25^{\text {th }}$ International Conference on Design Theory and Methodology (DTM)

- $37^{\text {th }}$ Mechanisms and Robotics Conference (MR)

- 2013 ASME/IEEE International Conference on Mechatronic and Embedded Systems and Applications (MESA2013)

- $7^{\text {th }}$ International Conference on Micro- and Nanosystems (MNS)

- $9^{\text {th }}$ International Conference on Multibody Systems, Nonlinear Dynamics, and Control (MSNDC)

- ASME 2013 Power Transmission and Gearing Conference (PTG)

- $22^{\text {nd }}$ Reliability, Stress Analysis, and Failure Prevention Conference (RSAFP)

- $25^{\text {th }}$ Conference on Mechanical Vibration and Noise (VIB)

- Groundbreaking Research in Engineering Design: Fueling Growth in Emerging Markets 


\title{
Proceedings of the ASME 2013 International Design Engineering Technical Conferences and Computers and Information in Engineering Conference

\section{A GALLERY OF ROOT LOCUS OF FRACTIONAL SYSTEMS}

\author{
J. A. Tenreiro Machado* \\ Institute of Engineering of Polytechnic of Porto \\ Dept. of Electrical Engineering \\ Rua Dr. Antonio Bernardino de Almeida, 431 \\ 4200-072 Porto, Portugal \\ Email: jtm@isep.ipp.pt
}

\begin{abstract}
The root locus (RL) is a classical tool for the stability analysis of integer order linear systems, but its application in the fractional counterpart poses some difficulties. Therefore, researchers have mainly preferred to adopt frequency based methods. Nevertheless, recently the $R L$ was considered for the stability analysis of fractional systems. One first method is by tacking advantage of commensurable expressions that occur when truncating fractional orders up to a finite precision. The second method consists of searching the complex plane for solutions of the characteristic equation using a numerical procedure. The resulting charts are insightful about the characteristics of the closed-loop system that outperform the frequency response methods. Given the limited know how in this particular topic and the shortage of literature, this study explores several types of fractional-order transfer functions and presents the corresponding $R L$.
\end{abstract}

\section{INTRODUCTION}

Fractional Calculus (FC) is a generalization of the classical integral and differential operators up to a non-integer order [1-5]. The concept of FC started with Leibniz but only in the last decades a significant number of applications emerged [6]. In fact, it was recognized that FC describes many phenomena, both natural and man made, tacking into consideration memory aspects that standard calculus neglects. One of the major areas of development is modelling and control [7,8]. Recently

*Address all correspondence to this author several works [9-12] filled an existing gap, namely the lack of textbooks written in an educational perspective and capable of leading common readers into the details of FC. In spite of the important contributions, there is still some lack of experience and intuition about the dynamics of a system described by a given fractional-order transfer function. Often researchers adopt the frequency domain for stability and dynamical analysis. Recently the root locus (RL) was tackled for the case of fractional systems [13-20]. This method constitutes a valid alternative to methods based in the Fourier transform, but poses some additional complexity. This papers addresses this topic in a educational perspective and is inspired in classical textbook in automatic control $[21,22]$ where readers can compare the alternative methods of system analysis by means of a table including several typical examples. Beraring these ideas in mind, in the next section are analysed several fractional systems and their dynamics studied with the RL method.

\section{DYNAMICAL ANALYSIS OF SEVERAL FRACTIONAL SYSTEM}

In this section are analysed several fractional order linear systems using the RL method. In several cases, for comparison purposes, are only adopted the open-loop frequency response, namely the polar diagram and the Bode plots of magnitude and phase, and the closed-loop time response $c(t)$ for a Dirac reference impulse. In the sequel $G_{i}(s)$ denotes the open-loop transfer function of the $i$-th system, $s$ represents the Laplace variable and 

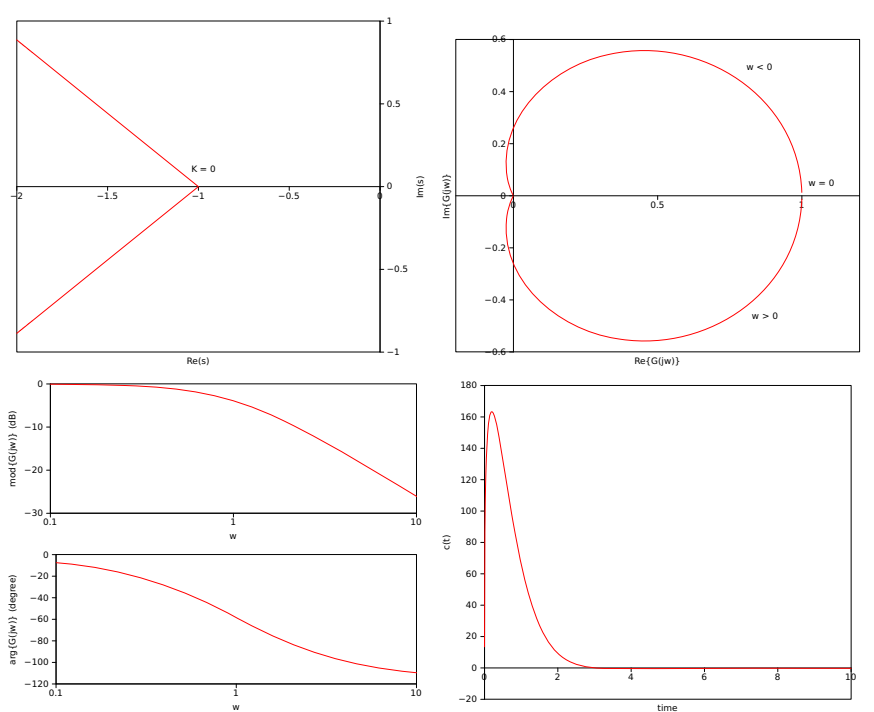

FIGURE 1. $G_{1}(s)=\frac{K}{(s+p)^{\alpha}}, p=1, \alpha=1.3$ : ROOT LOCUS, POLAR PLOT, BODE DIAGRAM, IMPULSE RESPONSE.

$K$ the gain. It is tackled the stability [23-27] of the closed-loop system with unit feedback $\frac{K G(s)}{1+K G(s)}$. At the end is also considered the case of a fractional PID controller $C(s)=K_{p}+K_{i} s^{-\lambda}+K_{d} s^{\mu}$ in series with the process $G_{i}(s)$ [28-30]. For studying the stability are applied the the following classical criteria:

Ultimate (or critical) gain $K_{u}: 1+K_{u} C(s) G(s)=0, \operatorname{Re}(s)=$ 0

Phase margin $P M:\left|C G\left(i \omega_{1}\right)\right|=1, P M=\arg \left\{C G\left(i \omega_{1}\right)\right\}+$ $\pi$

Gain margin $G M: \quad \arg \left\{C G\left(i \omega_{\pi}\right)\right\}=-\pi, \quad G M=$ $\left|C G\left(i \omega_{\pi}\right)\right|^{-1}$

In Table 1 are listed the main characteristics of the examples depicted in Figures 1-13. The white circle marks in the RL of Figures 12-13 correspond to the case of $K=1$, that is, the closedloop poles for the PID tuning adopted in [31].

\section{REFERENCES}

[1] Oldham, K., and Spanier, J., 1974. The fractional calculus: theory and application of differentiation and integration to arbitrary order. Academic Press, New York.

[2] Samko, S., Kilbas, A., and Marichev, O., 1993. Fractional integrals and derivatives: theory and applications. Gordon and Breach Science Publishers, Amsterdam.

[3] Miller, K., and Ross, B., 1993. An introduction to the fractional calculus and fractional differential equations. John Wiley and Sons, New York.

[4] Kilbas, A., Srivastava, H., and Trujillo, J., 2006. Theory and applications of fractional differential equations,
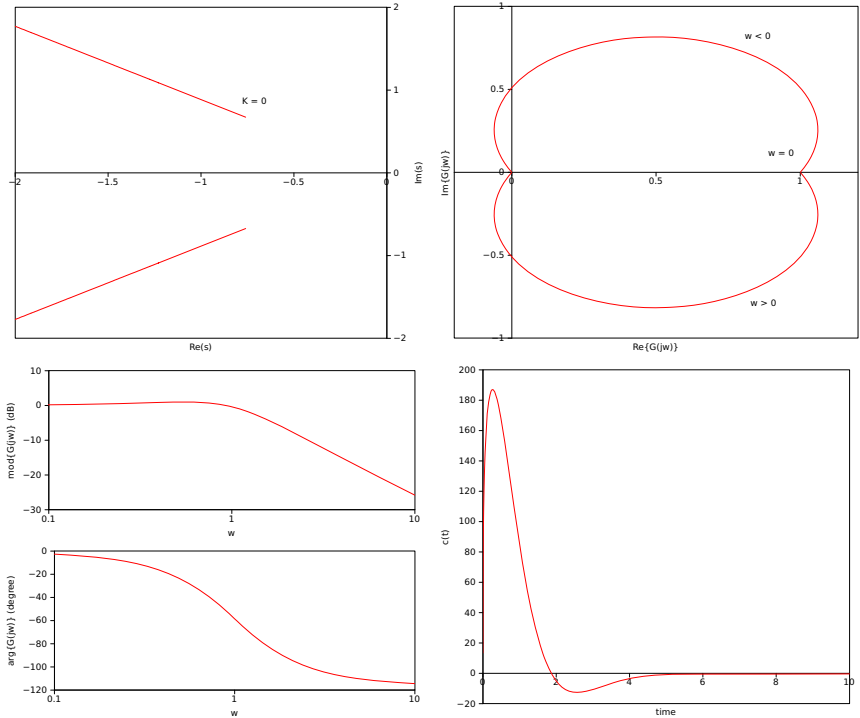

FIGURE 2. $G_{2}(s)=\frac{K}{s^{\alpha}+p}, p=1, \alpha=1.3$ : ROOT LOCUS, POLAR PLOT, BODE DIAGRAM, IMPULSE RESPONSE.
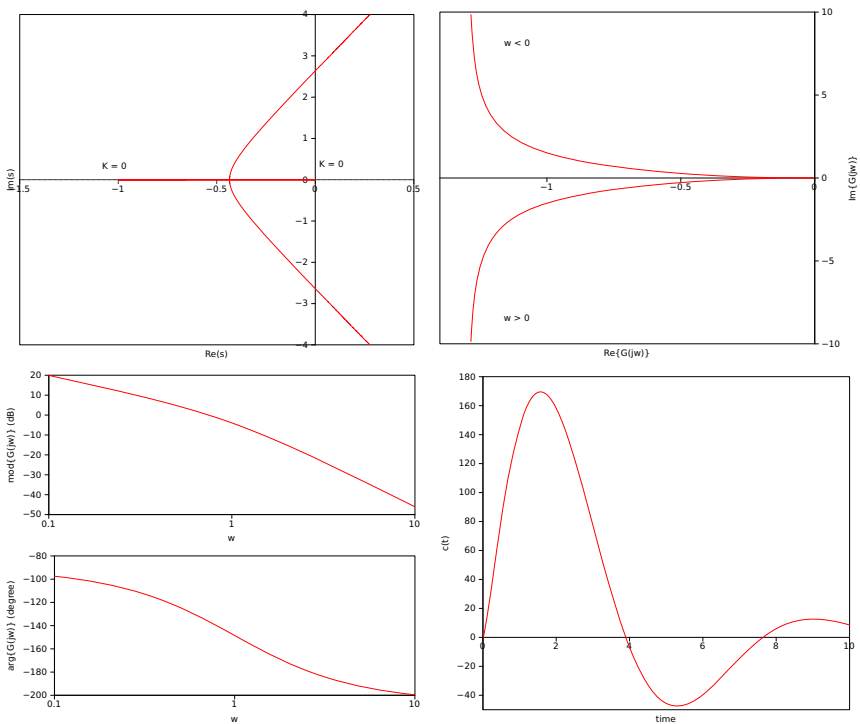

FIGURE 3. $G_{3}(s)=\frac{K}{s^{\alpha_{1}}(s+p)^{\alpha_{2}}}, p=1, \alpha_{1}=1, \alpha_{2}=1.3$ : ROOT LOCUS, POLAR PLOT, BODE DIAGRAM, IMPULSE RESPONSE.

Vol. 204. North-Holland Mathematics Studies, Elsevier, Amsterdam.

[5] Baleanu, D., Diethelm, K., Scalas, E., and Trujillo, J., 2012. Fractional calculus: Models and numerical methods. World Scientific, Boston, Mass, USA.

[6] J. Tenreiro Machado, V. Kiryakova, F. M., 2011. "Recent history of fractional calculus". Communications in Nonlin- 

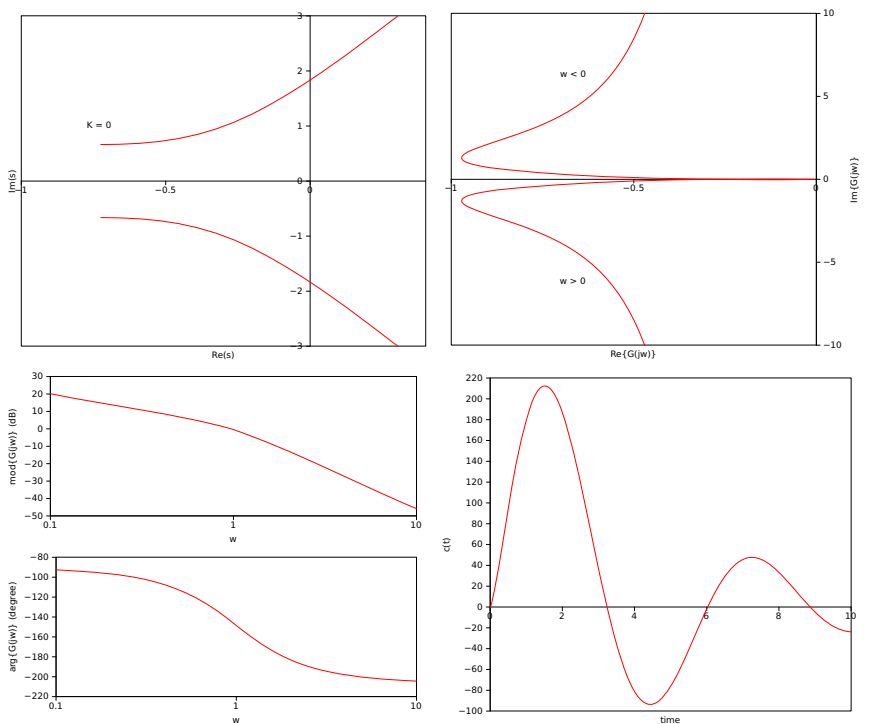

FIGURE 4. $\quad G_{4}(s)=\frac{K}{s^{\alpha_{1}}\left(s^{\alpha_{2}}+p\right)}, p=1, \alpha_{1}=1, \alpha_{2}=1.3$ : ROOT LOCUS, POLAR PLOT, BODE DIAGRAM, IMPULSE RESPONSE.
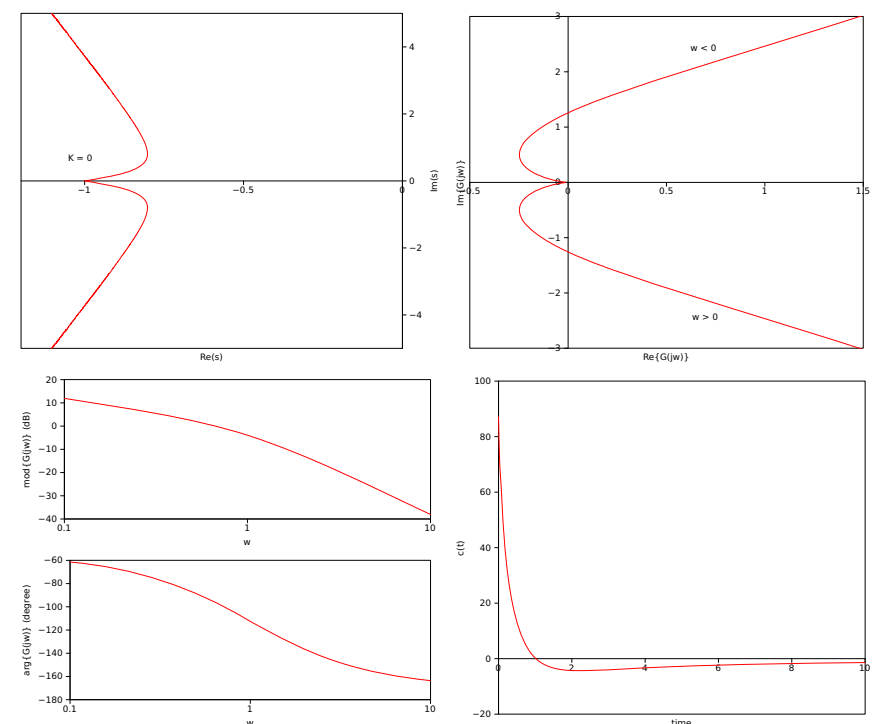

FIGURE 5. $\quad G_{5}(s)=\frac{K}{s^{\alpha_{1}}(s+p)^{\sigma_{2}}}, p=1, \alpha_{1}=0.6, \alpha_{2}=1.3$ : ROOT LOCUS, POLAR PLOT, BODE DIAGRAM, IMPULSE RESPONSE.

ear Science and Numerical Simulation, 16(3), pp. 11401153.

[7] Oustaloup, A., 1991. La commande CRONE: commande robuste d'ordre non entier. Hermès, Paris, France.

[8] Podlubny, I., 1998. Fractional differential equations, Volume 198: An Introduction to Fractional Derivatives, Fractional Differential Equations, to Methods of Their Solution,
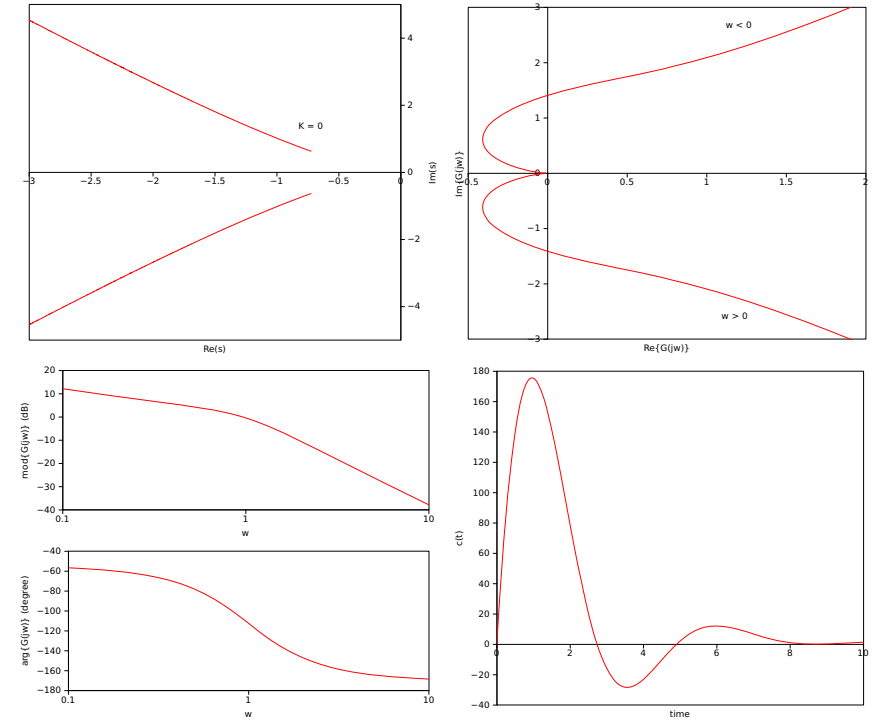

FIGURE 6. $\quad G_{6}(s)=\frac{K}{s^{\alpha_{1}}\left(s^{\alpha_{2}}+p\right)}, p=1, \alpha_{1}=0.6, \alpha_{2}=1.3$ : ROOT LOCUS, POLAR PLOT, BODE DIAGRAM, IMPULSE RESPONSE.
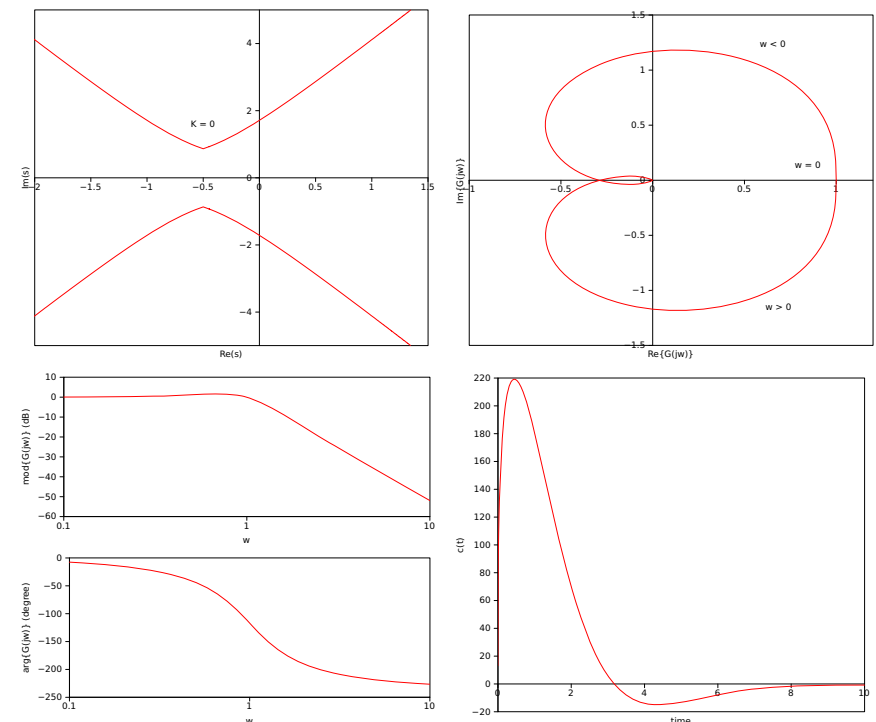

FIGURE 7. $\quad G_{7}(s)=\frac{K}{\left(s^{2}+2 \zeta \omega_{n} s+\omega_{n}^{2}\right)^{\alpha}}, \zeta=0.5, \omega_{n}=1, \alpha=1.3$ : ROOT LOCUS, POLAR PLOT, BODE DIAGRAM, IMPULSE RESPONSE.

Mathematics in Science and Engineering. Academic Press, San Diego.

[9] C.A. Monje, Y. Chen, B. V. D. X. V. F., 2010. Fractionalorder systems and controls: Fundamentals and applications. Springer, London.

[10] Riccardo Caponetto, Giovanni Dongola, L. F. I. P., 2010. 

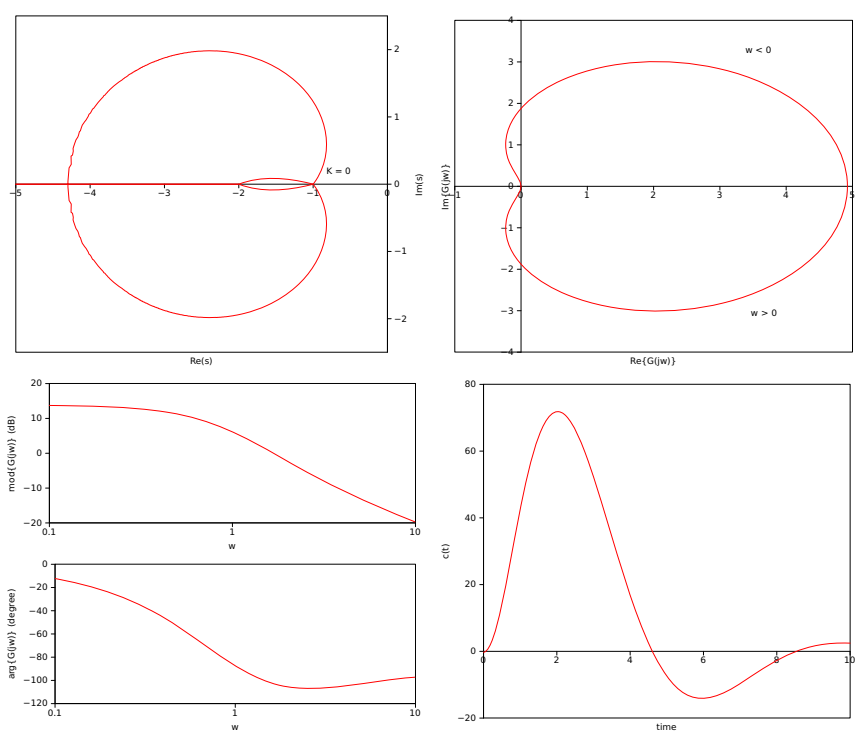

FIGURE 8. $\quad G_{8}(s)=\frac{K(s+z)^{\beta}}{(s+p)^{\alpha}}, p=1, z=2, \alpha=3.3, \beta=2.3$ : ROOT LOCUS, POLAR PLOT, BODE DIAGRAM, IMPULSE RESPONSE.
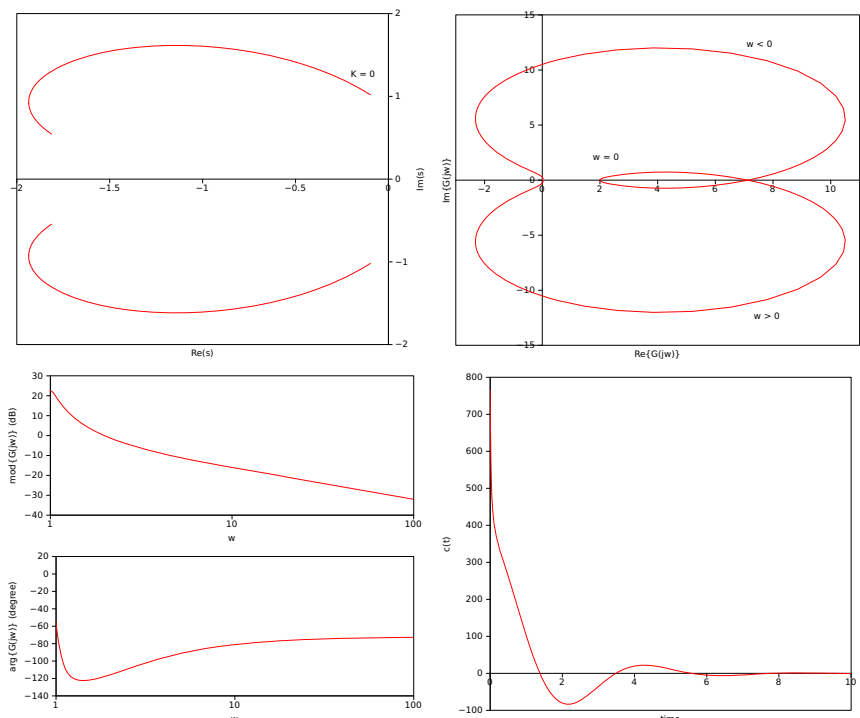

FIGURE 9. $\quad G_{9}(s)=\frac{K\left(s^{\beta}+z\right)}{s^{\alpha}+p}, p=1, z=2, \alpha=1.9, \beta=1.1:$ ROOT LOCUS, POLAR PLOT, BODE DIAGRAM, IMPULSE RESPONSE.

Fractional Order Systems: Modeling and Control Applications. World Scientific.

[11] Petráš, I., 2011. Nonlinear Physical Science: FractionalOrder Nonlinear Systems: Modeling, Analysis and Simulation. Nonlinear Physical Science. Springer, Higher Education Press.

[12] Duarte Valério, J. S. d. C. An Introduction to Fractional
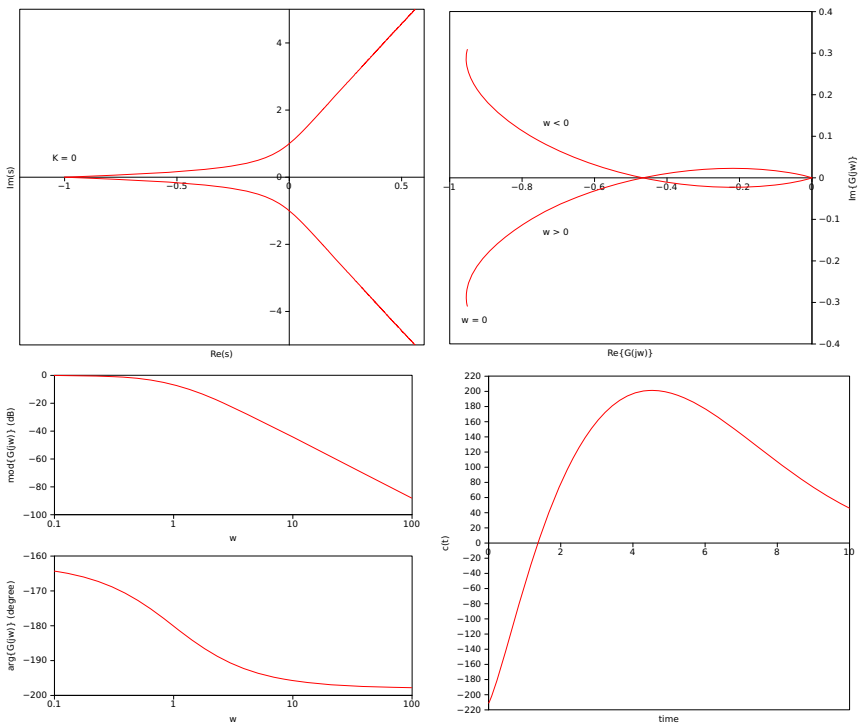

FIGURE 10. $\quad G_{10}(s)=\frac{K}{\left(s+p_{1}\right)^{\alpha_{1}}\left(s+p_{2}\right)^{\sigma_{2}}}, p_{1}=1, \alpha_{1}=1.3, p_{2}=-1$, $\alpha_{2}=0.9$ : ROOT LOCUS, POLAR PLOT, BODE DIAGRAM, IMPULSE RESPONSE.

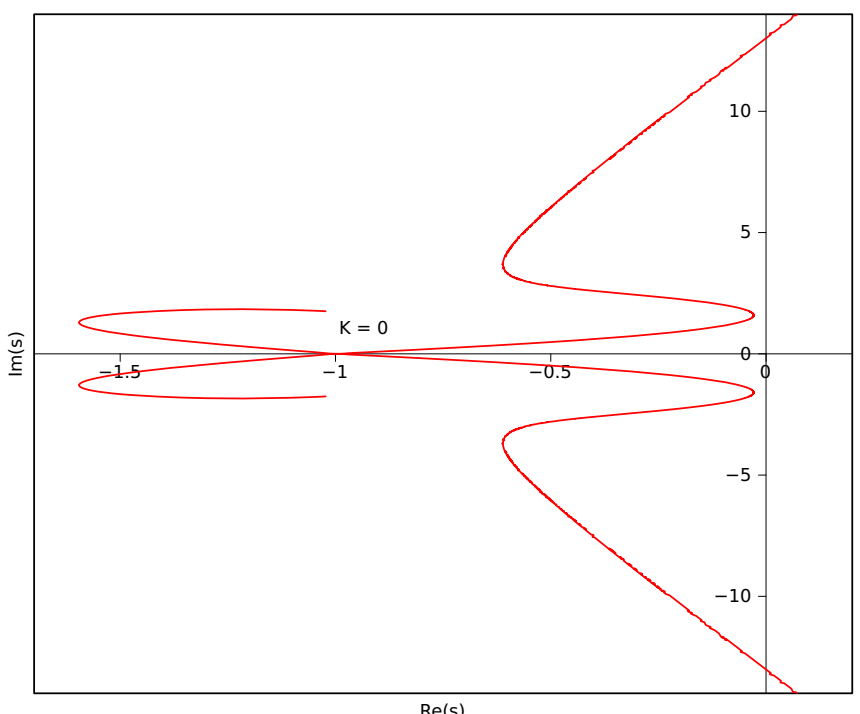

FIGURE 11. $G_{11}(s)=K \frac{\left(s^{2}+2 \zeta \omega_{n} s+\omega_{n}^{2}\right)^{\beta}}{(s+p)^{\alpha}}, p=1, \alpha=4.3, \zeta=0.5$, $\omega_{n}=2, \beta=1.1$ : ROOT LOCUS.

Control. IET, Stevenage.

[13] Evans, W. R., 1948. "Graphical analysis of control systems". Transactions of the American Institute of Electrical Engineers, 67(1), pp. 547-551.

[14] Evans, W. R., 1950. "Control systems synthesis by root locus method". Transactions of the American Institute of 


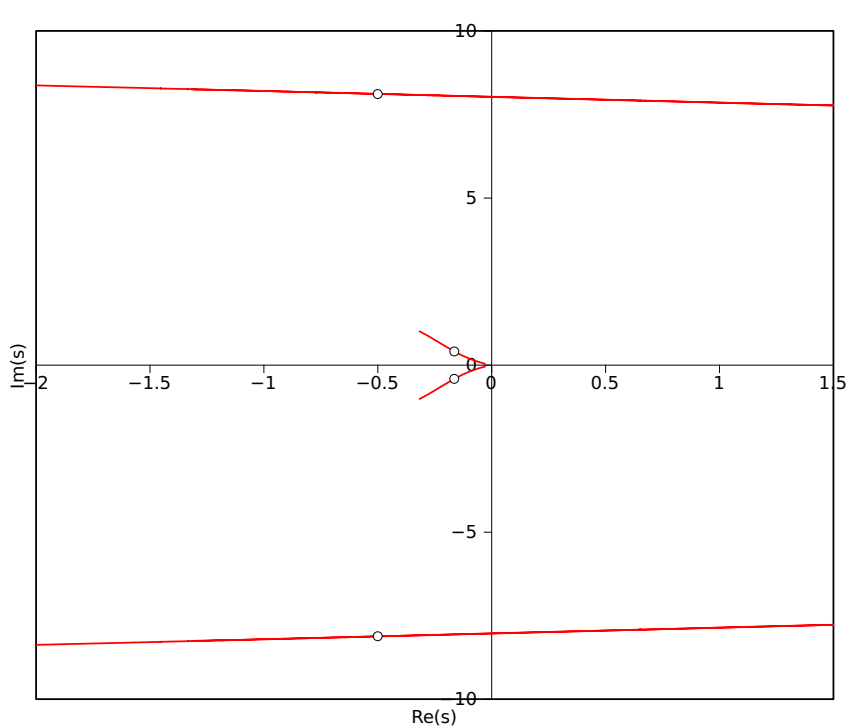

FIGURE 12. $G_{12}(s)=\frac{K}{1+\sqrt{s}} e^{-0.5 s}, \quad C(s)=0.6021+\frac{0.6187}{s^{1.3646}}+$ $0.3105 s^{1.0618}$ : ROOT LOCUS.

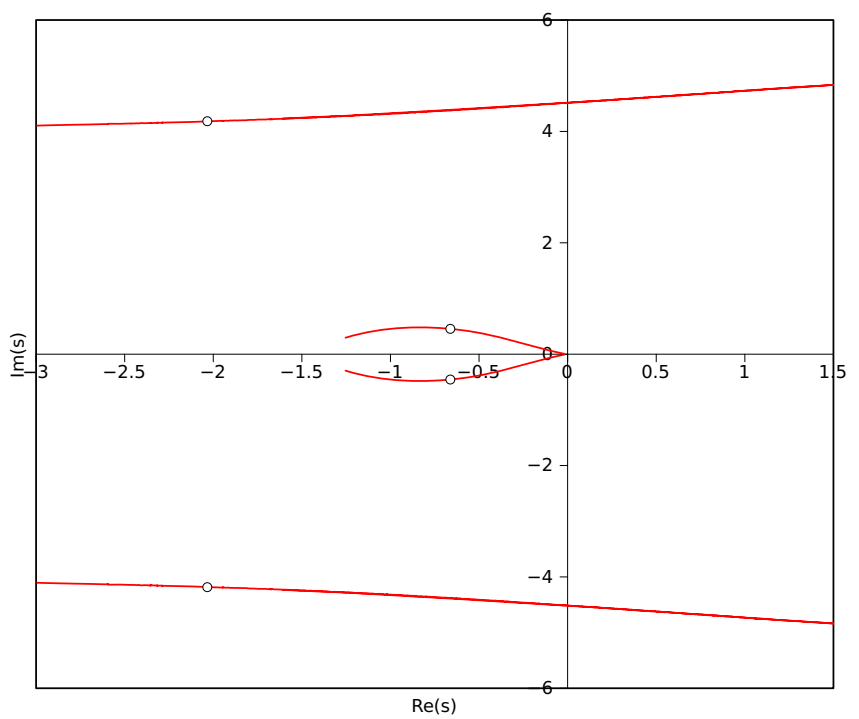

FIGURE 13. $G_{13}(s)=\frac{K}{1+\sqrt{s}} e^{-0.5 s}, \quad C(s)=1.4098+\frac{1.6486}{s^{1.1011}}-$ $0.2139 s^{0.1855}$ : ROOT LOCUS.

Electrical Engineers, 69(1), pp. 66-69.

[15] Krall, A. M., 1970. "The root locus method: a survey". SIAM Review, 12(1), pp. 64-72.

[16] A. M. Eydgahi, M. G., 2001. "Complementary root locus revisited”. IEEE Transactions on Education, 44(2), pp. 137-143.
[17] Farshad Merrikh-Bayat, M. A., 2008. "Extending the rootlocus method to fractional-order systems". Journal of Applied Mathematics, 2008(Article ID 528934), p. 13 pages.

[18] Farshad Merrikh-Bayat, M. K.-G., 2009. "An efficient numerical algorithm for stability testing of fractional-delay systems". ISA Transactions, 48(1), pp. 32-37.

[19] Merrikh-Bayat, F., 2010. "Stability of fractional-delay systems: A practical approach". In New Trends in Nanotechnology and Fractional Calculus Applications, D. Baleanu, Z. B. Guvenc, and J. A. T. Machado, eds. Springer Netherlands.

[20] Machado, J. T., 2011. "Root locus of fractional linear systems". Communications in Nonlinear Science and Numerical Simulation, 16(10), pp. 3855-3862.

[21] Richard C. Dorf, R. H. B., 2011. Modern Control Systems, twelfth ed. Advances in Biochemical Engineering Biotechnology. Pearson Prentice Hall, Berlin, Heidelberg.

[22] Charles L. Phillips, R. D. H., 1991. Feedback control systems. Prentice Hall.

[23] Petras, I., 2009. "Stability of fractional-order systems with rational orders: A survey". Fractional Calculus \& Applied Analysis, 12(3), pp. 269-298.

[24] Matignon, D., 1998. "Stability properties for generalized fractional differential systems". In ESAIM Proceedings, Systemes Differentiels Fractionnaires, Vol. 5, pp. 145-158.

[25] Matignon, D., 1996. "Stability results on fractional differential equations with applications to control processing". In Proceedings of the Computational Engineering in Systems Applications, pp. 963-968.

[26] C. F. Lorenzo, T. T. H., 1998. Initialization, conceptualization, and application in the generalized (fractional) calculus. Tech. Rep. TP-1998-208415, NASA, December.

[27] Buslowicz, M., 2008. "Stability of linear continuous-time fractional order systems with delays of the retarded type". Bulletin of the Polish Academy of Sciences Technical Sciences, 56(4), pp. 319-324.

[28] Machado, J. T., 1997. "Analysis and design of fractionalorder digital control systems". Systems Analysis, Modelling, Simulation, 27(2-3), pp. 107-122.

[29] Machado, J. T., 1999. "Fractional-order derivative approximations in discrete-time control systems". Systems Analysis, Modelling, Simulation, 34, pp. 419-434.

[30] Podlubny, I., 1999. "Fractional-order systems and $\mathrm{PI}^{\lambda} \mathrm{D}^{\mu}{ }_{-}$ controllers". IEEE Transactions on Automatic Control, 44(1), pp. 208-213.

[31] Duarte Valério, J. S. d. C., 2006. "Tuning of fractional PID controllers with Ziegler-Nichols-type rules". Signal Processing, 86(10), pp. 2771-2784. 
TABLE 1. LIST OF FRACTIONAL ORDER SYSTEMS.

\begin{tabular}{|c|c|c|c|}
\hline$i$ & $G_{i}(s)$ & Parameters & Stability \\
\hline 1 & $\frac{K}{(s+p)^{\alpha}}$ & $p=1, \alpha=1.3$ & \\
\hline 2 & $\frac{K}{s^{\alpha}+p}$ & $p=1, \alpha=1.3$ & $\omega_{1}=0.929, P M=126^{\circ}$ \\
\hline \multirow[t]{2}{*}{3} & $\frac{K}{s^{\alpha_{1}}(s+p)^{\alpha_{2}}}$ & $p=1$ & $K_{u}=10.14$ \\
\hline & & $\alpha_{1}=1, \alpha_{2}=1.3$ & $\omega_{1}=0.748, P M=42.7^{\circ}, \omega_{\pi}=2.633, G M=20.1 d B$ \\
\hline \multirow[t]{2}{*}{4} & $\frac{K}{s^{\alpha_{1}}\left(s^{\alpha_{2}}+p\right)}$ & $p=1$ & $K_{u}=3.60$ \\
\hline & & $\alpha_{1}=1, \alpha_{2}=1.3$ & $\omega_{1}=0.973, P M=33.2^{\circ}, \omega_{\pi}=1.838, G M=11.2 d B$ \\
\hline \multirow[t]{2}{*}{5} & $\frac{K}{s^{\alpha_{1}}(s+p)^{\alpha_{2}}}$ & $p=1$ & $\omega_{1}=0.67, P M=82.1^{\circ}$ \\
\hline & & $\alpha_{1}=0.6, \alpha_{2}=1.3$ & \\
\hline \multirow[t]{2}{*}{6} & $\frac{K}{s^{\alpha_{1}}\left(s^{\alpha_{2}}+p\right)}$ & $p=1$ & $\omega_{1}=0.964, P M=69.7^{\circ}$ \\
\hline & & $\alpha_{1}=0.6, \alpha_{2}=1.3$ & \\
\hline \multirow[t]{2}{*}{7} & $\frac{K}{\left(s^{2}+2 \zeta \omega_{n} s+\omega_{n}^{2}\right)^{\alpha}}$ & $\zeta=0.5, \omega_{n}=1$ & $K_{u}=3.43$ \\
\hline & & $\alpha=1.3$ & $\omega_{1}=1.0, P M=63.0^{\circ}, \omega_{\pi}=1.715, G M=10.8 \mathrm{~d} B$ \\
\hline \multirow[t]{2}{*}{8} & $\frac{K(s+z)^{\beta}}{(s+p)^{\alpha}}$ & $p=1, \alpha=3.3$ & $\omega_{1}=1.674, P M=76.7^{\circ}$ \\
\hline & & $z=2, \beta=2.3$ & \\
\hline \multirow[t]{2}{*}{9} & $\frac{K\left(s^{\beta}+z\right)}{s^{\alpha}+p}$ & $p=1, \alpha=1.9$ & $\omega_{1}=1.978, P M=63.8^{\circ}$ \\
\hline & & $z=2, \beta=1.1$ & \\
\hline \multirow[t]{2}{*}{10} & $\frac{K}{\left(s+p_{1}\right)^{\alpha_{1}}\left(s+p_{2}\right)^{\alpha_{2}}}$ & $p_{1}=1, \alpha_{1}=1.3$ & $K_{u}=2.15$ \\
\hline & & $p_{2}=-1, \alpha_{2}=0.9$ & $\omega_{1}=0.99, P M=6.5^{\circ}$ \\
\hline \multirow[t]{2}{*}{11} & $\frac{K\left(s^{2}+2 \zeta \omega_{n} s+\omega_{n}^{2}\right)^{\beta}}{(s+p)^{\alpha}}$ & $p_{1}=1, \alpha=4.3$ & $K_{u}=227.6$ \\
\hline & & $\zeta=0.5, \omega_{n}=2, \beta=1.1$ & $\omega_{1}=0.97, P M=25.9^{\circ}, \omega_{\pi}=13.1, G M=47.1 d B$ \\
\hline \multirow[t]{3}{*}{12} & $\frac{K}{1+\sqrt{s}} e^{-0.5 s}$ & $K_{p}=0.6021$ & $K_{u}=1.285$ \\
\hline & $P I^{\lambda} D^{\mu}$ & $K_{i}=0.6187, \lambda=1.3646$ & $\omega_{\pi}=8.03, G M=2.18 d B$ \\
\hline & & $K_{d}=0.3105, \mu=1.0618$ & $\omega_{1}=0.44, P M=43.0^{\circ}$ \\
\hline \multirow[t]{3}{*}{13} & $\frac{K}{1+\sqrt{s}} e^{-0.5 s}$ & $K_{p}=1.4098$ & $K_{u}=2.4$ \\
\hline & $P I^{\lambda} D^{\mu}$ & $K_{i}=1.6486, \lambda=1.1011$ & $\omega_{\pi}=4.60, G M=7.6 d B$ \\
\hline & & $K_{d}=-0.21395, \mu=0.1855$ & $\omega_{1}=1.06, P M=69.7^{\circ}$ \\
\hline
\end{tabular}

